\title{
Genetic variation in recombination in Drosophila. III. Regional effects on crossing over and effects on non-disjunction
}

\author{
Brian Charlesworth*, Ikue Mori† and \\ Deborah Charlesworth*
}

School of Biological Sciences, University of Sussex, Brighton BN1 9QG, U.K.

Multiply marked X, 2nd and 3rd chromosomes were used to study the patterns of regional specificity of effects on crossing over of chromosomes from a stock of $D$. melanogaster selected for high $G l-S b$ recombination. It was found that the $\mathrm{H}$ X chromosome increased crossover frequencies more or less uniformly throughout chromosome 3 , and did not significantly affect coincidence coefficients. The $\mathrm{H}$ 3rd chromosome increased crossing over most strongly in the proximal region of chromosome 3 , and in the distal region of the $X$ chromosome, although effects could be detected on other parts of the $X$ and 3 rd chromosomes. 2nd chromosome recombination was, however, reduced by the $H$ rrd chromosome. Coincidence coefficients were increased in chromosome 3 by the $\mathbf{H}$ 3rd chromosome, but no significant effects on the $X$ or 2 nd chromosomes could be detected.

The $\mathbf{H}$ genome significantly reduced the frequency of $\mathbf{X}$ chromosome non-disjunction, but had no detectable effect on chromosome 3 non-disjunction. Heterozygosity for a 2 nd chromosome balancer (SM 1 ) increased 3rd chromosome non-disjunction, but had no effect on the $X$.

These findings are discussed in relation to other genetic studies of Drosophila recombination, and to the problem of the evolutionary modification of recombination rates.

\section{INTRODUCTION}

In the previous papers in this series (Charlesworth and Charlesworth $1985 a, b)$, we have described some experiments on artificial selection on recombination frequencies in female Drosophila melanogaster, and presented the results of genetic analysis of the difference between an unselected control stock $(\mathrm{C})$ and a selected line $(\mathrm{H})$ with an increased frequency of recombination between the 3 rd chromosome markers $G l$ and $S b$. These experiments were motivated by the wish to obtain a better understanding of the properties of naturally occurring genetic modifiers of recombination, since these properties play an important role in theories of the evolutionary modification of recombination (Maynard Smith, 1978). A critical

\footnotetext{
* Present address: Department of Biology, The University of Chicago, 1103 East 57th Street, Chicago, IL 60637, USA.

$\dagger$ Present address: Department of Genetics, Washington University School of Medicine, 4566 Scott Avenue, St. Louis, MO 63110 , USA.
}

parameter in these theories is the degree of linkage between recombination modifying genes and the chromosomal regions which they affect; recombination modifiers that are only loosely linked to loci under natural selection are unlikely to experience a strong selective advantage, compared with tightly linked modifiers (Nei, 1967; 1969; Maynard Smith, 1978). For this reason, it is important to accumulate evidence concerning the regional specificity of the effects of recombination modifiers.

In this paper, we describe the results of some experiments designed to provide such evidence for the recombination genes detected in our earlier experiments. We also describe experiments to test the effects of our recombination genes on the rates of $\mathrm{X}$ chromosome and autosome non-disjunction. The study of meiotic mutants of Drosophila with drastic effects of reducing recombination has shown that they normally also increase the rate of non-disjunction, due to the increase in frequency of non-exchange tetrads with reduced 
crossing over, and the consequent increased rate of entry of chromosomes into the distributive pairing pool where non-homologous associations of chromosomes are possible (Baker and Hall, 1976; Lindsley and Sandler, 1977). One might expect the converse effect on non-disjunction for genes that increase crossover frequencies. It could be argued that such a decrease in non-disjunction rate would play a significant role in the evolutionary maintenance of recombination (Darlington, 1958, Chaps. 15, 24; but see White, 1973, pp. 169-170 and Maynard Smith, 1978, pp. 72-73).

\section{MATERIALS AND METHODS}

The experimental procedures for rearing flies and scoring progenies were as described in the earlier papers in this series (Charlesworth and Charlesworth, 1985a, b).

\section{(i) Assays of recombination}

Recombination between genes on the $X$ and 2 nd chromosomes was assayed using the multiply marked $\mathrm{X}$ and 2 nd chromosomes $y c v v f c a r$ and aldp b pr cn px sp respectively, supplied by the Bowling Green stock centre. These will be referred to as ycar and alsp in what follows. 3 rd chromosome recombination was assayed using the rucuca multiply marked chromosome (Charlesworth and Charlesworth, 1985b). The markers scored in these assays are shown in figs. 1 and 4 , together with their map positions. All assays of recombination employed vial-reared progenies, as described by Charlesworth and Charlesworth (1985b). Vials with less than 15 flies were not analysed.

\section{(ii) Assays of non-disjunction}

Non-disjunction of the $X$ chromosome in females was assayed by crossing males carrying the $\mathrm{X}$ chromosome balancer $F M 7$ to females of the appropriate stock. Bottle crosses following our standard procedure (Charlesworth and Charlesworth, 1985a) were used throughout. Exceptional females are readily scored as lacking the Bar-eye phenotype; whenever possible, the exceptional females were progeny tested to verify their status. All putative exceptions turned out to be genuine. The viability of FM7 males was so poor under our conditions that we could not reliably score the frequency of exceptional males. In any case, exceptional males can be produced by other mechanisms, so that females provide more reliable data (Roberts, 1962).

Non-disjunction of chromosome 3 in females was scored by crossing males from the compound 3 rd chromosome stock $\mathrm{C}(3 L), h^{\prime} / h^{2} ; \mathrm{C}(3 R),+$, supplied by Dr W. R. Engels, University of Wisconsin, to females of the desired genotype. In the absence of breakdown of the compound chromosome, which is a rare event (Holm, 1976), only nullo-3 or diplo-3 gametes from the female parents (produced by non-disjunction) can generate viable progeny. In order to estimate non-disjunction frequencies, control crosses were carried out simultaneously, in which females of the same genotypes as the experimental crosses were crossed to FM7 males, and the emergences recorded.

\section{(iii) Statistical procedures}

Tests of significance of differences in frequencies were carried out by $t$-tests, analyses of variance or contingency $\chi^{2}$, as appropriate. The $t$-tests and analyses of variance were done using angular transforms of frequencies; as before, individual culture values were not weighted by numbers of flies per culture (Charlesworth and Charlesworth, $1985 b$ ). The means and standard errors shown in the tables and figures were calculated directly from the untransformed data.

\section{REGIONAL SPECIFICITY OF GENETIC EFFECTS ON RECOMBINATION}

\section{(i) Effect of the $X$ chromosome on chromosome 3}

Females of the genotypes shown below were crossed to rucuca males, and each progeny individual was scored for the markers shown in fig. $1(\mathrm{X}$ on 3$)$.

$$
\mathrm{C}: \frac{\mathrm{C}}{\mathrm{C}} \frac{\mathrm{Cy}}{\mathrm{C}} \frac{S b_{\mathrm{C}}}{\text { rucuca }} \quad \mathrm{H}: \frac{\mathrm{H}}{\mathrm{H}} \frac{C y}{\mathrm{C}} \frac{S b_{\mathrm{C}}}{\text { rucuca }}
$$

$\mathrm{C}$ and $\mathrm{H}$ indicate chromosomes derived from the isogenic control and high recombination stocks, respectively (Charlesworth and Charlesworth $1985 a, b) ; C y$ indicates the 2nd chromosome balancer $S M 1$, heterozygosity for which prevents sterility of the $\mathrm{H}$ females. The comparison between $\mathrm{C}$ and $\mathrm{H}$ thus measures the effect of the $\mathrm{HX}$ chromosome on chromosome 3 on a background of $\mathrm{C} \mathrm{X}$ and 2 nd chromosomes. (The $\mathrm{cu}$ gene from rucuca was not scored, since its phenotype is easily confused with that of $C y$.) 


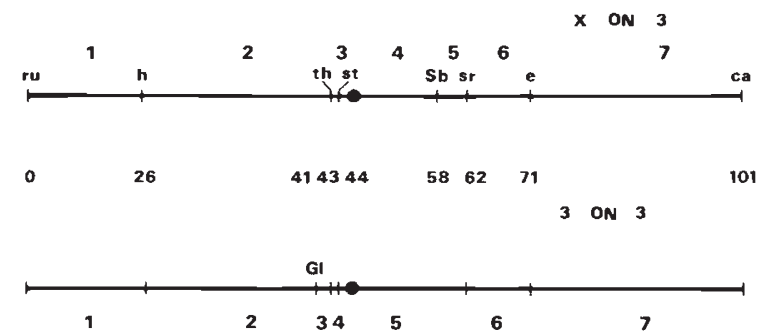

Figure 1 Approximate map positions of the markers used in the measurements of the effect of the $\mathrm{X}$ and 3 rd chromosomes on chromosome 3 recombination ( $X$ on 3 and 3 on 3 , respectively). The codes for the map intervals in tables 1-6 and figs. 2 and 3 are also indicated.

Replicates of both these classes of mating were set up over six weekly blocks. In all, $59 \mathrm{C}$ and 59 $\mathrm{H}$ vials were scored, representing 5979 and 4490 flies respectively. Analyses of variance did not reveal any significant block effects, so that the results described below are based on data pooled across blocks.

Table 1 shows the means and standard errors for the crossover frequencies in the seven intervals $r u$ - $h, h$-th, th-st, st-Sb, Sb-sr, sr-e and e-ca. Table 2

Table 1 Chromosome 3 crossover frequencies of females with $\mathrm{H}$ or $\mathrm{C} \mathrm{X}$ chromosomes

\begin{tabular}{|c|c|c|c|}
\hline Interval & $\begin{array}{l}\text { C Mean } \\
( \pm \text { st. error })\end{array}$ & $\begin{array}{l}\text { H Mean } \\
( \pm \text { st. error })\end{array}$ & $t$ \\
\hline 1 & $0.263 \pm 0.007$ & $0.300 \pm 0.007$ & $3 \cdot 69 \ddagger$ \\
\hline 2 & $0.219 \pm 0.007$ & $0.230 \pm 0.007$ & 1.05 \\
\hline 3 & $0.005 \pm 0.001$ & $0.006 \pm 0.001$ & 0.27 \\
\hline 4 & $0.136 \pm 0.006$ & $0.157 \pm 0.006$ & $2 \cdot 28^{*}$ \\
\hline 5 & $0.050 \pm 0.004$ & $0.058 \pm 0.004$ & $1 \cdot 17$ \\
\hline 6 & $0.111 \pm 0.006$ & $0.109 \pm 0.006$ & $-1 \cdot 00$ \\
\hline 7 & $0.331 \pm 0.008$ & $0.372 \pm 0.008$ & $3 \cdot 50 \ddagger$ \\
\hline
\end{tabular}

The $t$ values each have $116 \mathrm{df}$.

$* p<0.05$

$\dagger p<0.01$

$\ddagger p<0.001$ shows the means and standard errors for the double crossover frequencies and coincidence coefficients for adjacent pairs of intervals. Fig. 2 displays the ratios $\mathrm{H} / \mathrm{C}$ for the mean crossover frequencies and coincidence coefficients.

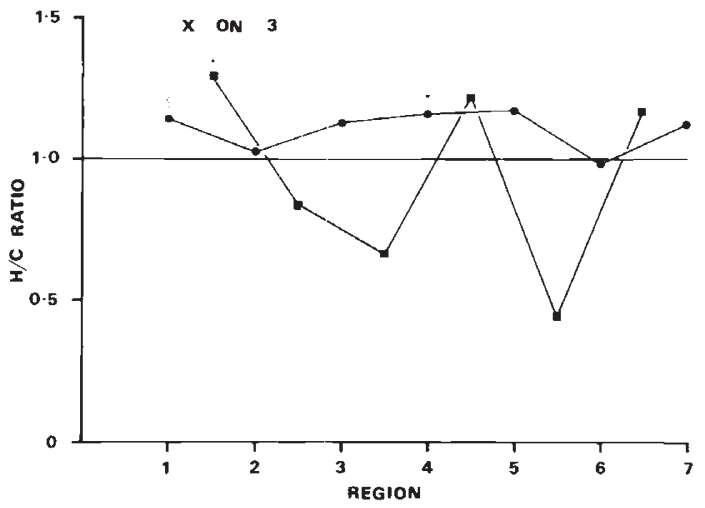

Figure 2 Ratios of the means of $\mathrm{H}$ females to $\mathrm{C}$ females for crossover frequencies (circles) and coincidence coefficients (squares), for the effect of the $\mathrm{X}$ chromosome on chromosome 3.

It can be seen that crossover frequencies are increased more or less uniformly along chromosome 3 by substituting the $\mathrm{H}$ for the $\mathrm{C} \mathrm{X}$ chromosome; the apparent lack of any effect in some regions could easily be due to sampling fluctuations. The average percentage increase is 11 per cent, which is considerably smaller than the value of 31 per cent for $G l-S b$ recombination in table 2 of Charlesworth and Charlesworth $(1985 b)$; this difference could be due to chance, however.

Table 2 shows that double crossover frequencies and coincidence coefficients do not differ significantly, except for interval $1(r u-h)$, where both show increases that are significant at the $p<0.05$ level. Because of the low double crossover frequencies for many of the pairs of intervals, the sampling

Table 2 Chromosome 3 double crossover frequencies and coincidence coefficients of females with $\mathrm{H}$ or $\mathrm{C} \mathrm{X}$ chromosomes

\begin{tabular}{|c|c|c|c|c|c|c|}
\hline \multirow[b]{2}{*}{ Intervals } & \multicolumn{3}{|c|}{ Double Crossover Frequencies } & \multicolumn{3}{|c|}{ Coincidence Coefficients } \\
\hline & C Mean & H Mean & $t$ & C Mean & H Mean & $t$ \\
\hline $2 / 3$ & $0.0007 \pm 0.0005$ & $0.0007 \pm 0.0005$ & $-0 \cdot 22$ & $0.629 \pm 0.412$ & $0.531 \pm 0.351$ & $-0 \cdot 18$ \\
\hline $3 / 4$ & $0.0012 \pm 0.0005$ & $0.0010 \pm 0.0005$ & -0.09 & $1.754 \pm 0.688$ & $1 \cdot 157 \pm 0.536$ & -0.68 \\
\hline $4 / 5$ & $0.0030 \pm 0.0008$ & $0.0032 \pm 0.0008$ & 0.08 & $0.441 \pm 0.084$ & $0.349 \pm 0.084$ & -0.65 \\
\hline
\end{tabular}

The variances of the mean coincidence coefficients were computed from the variances of the means of the single and double crossover frequencies for the intervals concerned, using the delta-method formula for the variance of a ratio. 
variances of the coincidence coincidents are mostly very large, unfortunately, and so the lack of statistical significance may not necessarily imply a true absence of effects.

Table 3 shows the frequencies of recovered strands with $0,1, \ldots$ exchanges, and the corresponding tetrad frequencies calculated by the

Table 3 Frequencies of different strand and tetrad classes for chromosome 3 in females with $\mathrm{H}$ or $\mathrm{C} \mathrm{X}$ chromosomes

\begin{tabular}{|c|c|c|c|}
\hline \multirow{2}{*}{$\begin{array}{l}\text { No. of } \\
\text { Exchanges }\end{array}$} & \multicolumn{2}{|c|}{ Mean Frequencies } & \multirow[b]{2}{*}{$t$} \\
\hline & C & $\mathrm{H}$ & \\
\hline \multicolumn{4}{|l|}{ Strands } \\
\hline 0 & $0 \cdot 237 \pm 0 \cdot 007$ & $0 \cdot 208 \pm 0 \cdot 008$ & $-2 \cdot 96+$ \\
\hline 1 & $0.458 \pm 0.006$ & $0.431 \pm 0.008$ & $-2.61 *$ \\
\hline 2 & $0.258 \pm 0.007$ & $0.288+0.009$ & $2 \cdot 73 \dagger$ \\
\hline 3 & $0.045 \pm 0.003$ & $0.069+0.006$ & $3 \cdot 59$ \\
\hline 4 & $0.002+0.001$ & $0 \cdot 005 \pm 0 \cdot 001$ & $2 \cdot 11^{*}$ \\
\hline \multicolumn{4}{|l|}{ Tetrads } \\
\hline 0 & $-0.006 \pm 0 \cdot 016$ & $0.001+0.016$ & 0.31 \\
\hline 1 & $0.141 \pm 0.051$ & $0.086 \pm 0 \cdot 051$ & -0.77 \\
\hline 2 & $0.533 \pm 0.071$ & $0.434 \pm 0 \cdot(071$ & -0.98 \\
\hline 3 & $0 \cdot 303 \pm 0.047$ & $0.412 \pm 0.047$ & 1.64 \\
\hline 4 & $0.029 \pm 0.016$ & $0.063 \pm 0.016$ & $1 \cdot 51$ \\
\hline \multicolumn{4}{|c|}{ Mean Crossover Numbers } \\
\hline Strands & $1 \cdot 117 \pm 0 \cdot 013$ & $1 \cdot 233 \pm 0 \cdot 018$ & $5 \cdot 19 \neq$ \\
\hline Tetrads & $2 \cdot 234 \pm 0 \cdot 032$ & $2.465 \pm 0.032$ & $5 \cdot 19$ \\
\hline
\end{tabular}

method of Weinstein $(1936 ; 1958)$. It can be seen that the $\mathrm{H}$ females show significantly lower frequencies of 0 and 1 exchange strands than the C. females, while the frequencies of 2,3 and 4 exchange strands are increased significantly. The differences in tetrad frequencies are all nonsignificant, probably because the tetrad frequencies have much higher standard errors than the exchange frequencies. The mean numbers of crossovers per strand and per tetrad are both significantly increased in $\mathrm{H}$ females.

\section{(ii) Effect of the 3rd chromosome on chromosome 3}

Females of the genotypes below were crossed to rucuca males, and the progeny scored for the markers shown in fig. 1 (3 on 3 ). ( $c u$ was again not scored.)

$$
\mathrm{C}: \frac{\mathrm{H}}{\mathrm{H}} \frac{C y}{\mathrm{H}} \frac{G l_{\mathrm{C}}}{\text { rucuca }} \quad \mathrm{H}: \frac{\mathrm{H}}{\mathrm{H}} \frac{C y}{\mathrm{H}} \frac{G l_{\mathrm{H}}}{\text { rucuca }}
$$

The comparison between $\mathrm{H}$ and $\mathrm{C}$ thus measures the effect of the $G l_{\mathrm{H}} 3 \mathrm{rd}$ chromosome on $3 \mathrm{rd}$ chromosome recombination on an $\mathrm{H}$ background; as described in the previous paper (Charlesworth and Charlesworth, $1985 \mathrm{~b}), \mathrm{Gl}_{\mathrm{H}}$ contributes the entire 3 rd chromosome effect in the high recombination stock.

Table 4 shows the crossover frequency comparisons of $\mathrm{H}$ and $\mathrm{C}$ females, table 5 shows the double crossover and coincidence comparisons,

Table 4 Chromosome 3 crossover frequencies of females with $\mathrm{H}$ or C. 3rd chromosomes

\begin{tabular}{llll}
\hline Interval & C Mean & H Mean & $t$ \\
\hline 1 & $0.283 \pm 0.008$ & $0.300 \pm 0.008$ & 1.41 \\
2 & $0.186 \pm 0.007$ & $0.212 \pm 0.007$ & $2.25^{*}$ \\
3 & $0.031 \pm 0.004$ & $0.044 \pm 0.004$ & $2.35^{*}$ \\
4 & $0.007 \pm 0.001$ & $0.009 \pm 0.001$ & 1.25 \\
5 & $0.186 \pm 0.008$ & $0.227 \pm 0.008$ & $3.78 \ddagger$ \\
6 & $0.095 \pm 0.005$ & $0.120 \pm 0.005$ & $3.58 \ddagger$ \\
7 & $0.360 \pm 0.008$ & $0.386 \pm 0.008$ & $2.10^{*}$ \\
\hline
\end{tabular}

The $t$ values each have $131 \mathrm{df}$.

and table 6 shows the strand and tetrad class results. Fig. 3 displays the ratios of the $H$ to the $\mathrm{C}$ means for single crossover frequencies and coincidence coefficients. The experiments were carried out over seven blocks, involving $75 \mathrm{C}$ and $70 \mathrm{H}$ vials ( 5700 and 5932 flies, respectively). Block effects were found to be significant for several of

Table 5 Chromosome 3 double crossover frequencies and coincidence coeflicients of females with $\mathrm{H}$ or C 3 rd chromosomes

\begin{tabular}{|c|c|c|c|c|c|c|}
\hline \multirow[b]{2}{*}{ Intervals } & \multicolumn{3}{|c|}{ Double Crossover Frequencies } & \multicolumn{3}{|c|}{ Coincidence Coefficients } \\
\hline & C Mean & H Mean & $t$ & C: Mean & H Mean & $t$ \\
\hline $1 / 2$ & $0 \cdot 0176 \pm 0 \cdot 0027$ & $0.0379 \pm 0 \cdot 0027$ & $4 \cdot 48 \div$ & $0.335 \pm 0.046$ & $0.598 \div 0.038$ & $4 \cdot 384$ \\
\hline $2 / 3$ & $0.0033+0.0019$ & $0.0079 \pm 0.0019$ & $2 \cdot 82^{*}$ & $0.580 \pm 0.329$ & $0 \cdot 849 \pm 0 \cdot 203$ & $0 \cdot 70$ \\
\hline $3 / 4$ & 0 & 0 & 0 & 0 & - n & - \\
\hline $4 / 5$ & $0 \cdot 0009 \pm 0 \cdot 0006$ & $0 \cdot 0020 \pm 0 \cdot 0006$ & $1 \cdot 23$ & $0.718 \pm 0.458$ & $0.997+0.294$ & 0.51 \\
\hline $5 / 6$ & $0.0048 \pm 0.0005$ & $0 \cdot 0106 \pm 0 \cdot 0047$ & $3 \cdot 12 \dagger$ & $0 \cdot 268 \pm 0 \cdot 085$ & $0.387 \pm 0.055$ & $1 \cdot 18$ \\
\hline $6 / 7$ & $0.0176 \pm 0.0025$ & $0.0346 \pm 0.0025$ & $4 \cdot 24 \ddagger$ & $0.514 \pm 0.068$ & $0.747 \pm 0 \cdot 052$ & $2 \cdot 71 \dagger$ \\
\hline
\end{tabular}


Table 6 Frequencies of different strand and tetrad classes for chromosome 3 in females with $\mathrm{H}$ or $\mathrm{C} 3$ rd chromosomes

\begin{tabular}{|c|c|c|c|}
\hline \multirow{2}{*}{$\begin{array}{l}\text { No. of } \\
\text { Exchanges }\end{array}$} & \multicolumn{2}{|c|}{ Mean Frequencies } & \multirow[b]{2}{*}{$t$} \\
\hline & $\mathrm{C}$ & $\mathrm{H}$ & \\
\hline \multicolumn{4}{|l|}{ Strands } \\
\hline 0 & $0.220 \pm 0.007$ & $0.192 \pm 0.006$ & $-2.95 \dagger$ \\
\hline 1 & $0.443 \pm 0.009$ & $0.416 \pm 0.007$ & $-2 \cdot 28^{*}$ \\
\hline 2 & $0.270 \pm 0.008$ & $0.308 \pm 0.007$ & $3 \cdot 65 \neq$ \\
\hline 3 & $0 \cdot 050 \pm 0.004$ & $0.073 \pm 0.004$ & $4 \cdot 06 \neq$ \\
\hline 4 & $0.003 \pm 0.007$ & $0.011 \pm 0.002$ & $3.48 \ddagger$ \\
\hline 5 & $0.000 \pm 0.000$ & $0.001 \pm 0.003$ & 1.96 \\
\hline \multicolumn{4}{|l|}{ Tetrads } \\
\hline 0 & $-0.011 \pm 0.014$ & $0.025 \pm 0.014$ & $1 \cdot 76$ \\
\hline 1 & $0.112 \pm 0.045$ & $-0.052 \pm 0.045$ & $-2 \cdot 58^{*}$ \\
\hline 2 & $0.535 \pm 0.064$ & $0.614 \pm 0.064$ & 0.87 \\
\hline 3 & $0.306 \pm 0.055$ & $0.248 \pm 0.055$ & -0.75 \\
\hline 4 & $0.048 \pm 0.028$ & $0.146 \pm 0.028$ & $2 \cdot 51^{*}$ \\
\hline 5 & $0.000 \pm 0.008$ & $0.020 \pm 0.008$ & $1 \cdot 81$ \\
\hline \multicolumn{4}{|c|}{ Mean Crossover Numbers } \\
\hline Strands & $1 \cdot 146 \pm 0 \cdot 021$ & $1 \cdot 297 \pm 0.016$ & $5 \cdot 71 \ddagger$ \\
\hline Tetrads & $2 \cdot 293 \pm 0 \cdot 107$ & $2 \cdot 603 \pm 0 \cdot 107$ & $2 \cdot 07^{*}$ \\
\hline
\end{tabular}

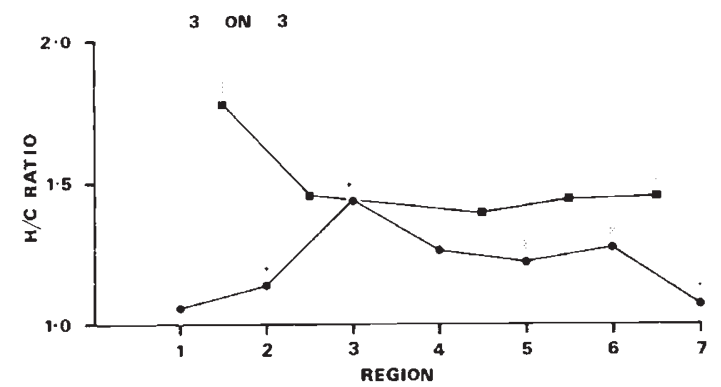

Figure 3 As for fig. 2, except that the effect is that of the 3 rd chromosome on chromosome 3 .

the comparisons, and have therefore been removed from the analysis of variance and comparisons of means.

In contrast to the results for the $\mathrm{X}$ chromosome effect, there seems to be marked regional specificity of the effects of the $\mathrm{H}$ chromosome 3 on 3 rd chromosome crossover frequencies. The effect is most marked towards the proximal regions, and falls off towards the tips. A comparison between the mean logarithm of the ratio of $\mathrm{H}$ to $\mathrm{C}$ for the crossover frequencies in the distal regions 1 and 7 with the mean for the other regions gives a significant difference $(z=2.68, p<0.01$ on a normal variate test).

Furthermore, both double crossover frequencies and coincidence coefficients are increased in $\mathrm{H}$ females, at least in some regions. The consistency of the pattern suggests that this effect is general throughout the chromosome, despite the lack of significance in some cases.

Some significant effects on tetrad frequencies are also detected in this case; there is a significant decrease in 1 exchange tetrads, and an increase in 4 exchange tetrads in $\mathrm{H}$ females.

\section{(iii) Effect of the 3rd chromosome on the $X$ chromosome}

Females of the genotypes below were crossed to ycar males, and the progeny scored for the markers shown in fig. 4 ( 3 on $X)$.

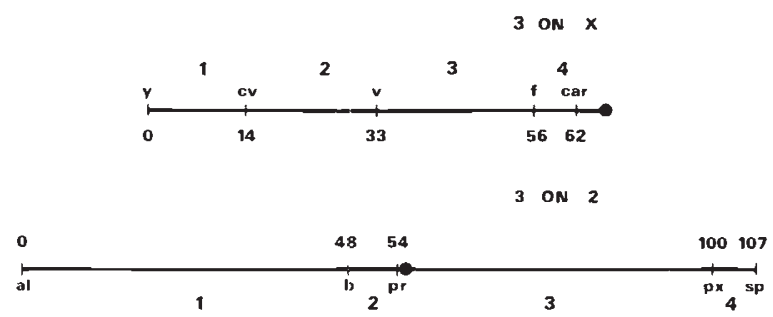

Figure 4 Approximate map positions of the markers used in the measurements of the effect of the 3rd chromosome on the $\mathrm{X}$ chromosome ( 3 on $\mathrm{X}$ ) and chromosome 2 ( 3 on 2 ). The codes for the map intervals in tables $7-11$ and figs. 5 and 6 are also indicated.

$$
\mathrm{C}: \frac{\mathrm{H}}{y c a r} \frac{C y}{\mathrm{H}} \frac{T M 6}{G l_{\mathrm{C}}} \quad \mathrm{H}: \frac{\mathrm{H}}{y c a r} \frac{C y}{\mathrm{H}} \frac{T M 6}{G l_{\mathrm{H}}}
$$

The comparison between $\mathrm{H}$ and $\mathrm{C}$ measures the effect (on an $\mathrm{H}$ background) of the $G l_{\mathrm{H}} 3 \mathrm{rd}$ chromosome, heterozygous over the balancer TM6, on $\mathrm{X}$ chromosome recombination. The experiments were carried out over seven weekly blocks, involving $138 \mathrm{C}$ and $105 \mathrm{H}$ vials (8269 and 6957 flies, respectively. Block effects were significant in some instances, so that blocks were not pooled in the analyses of variance and comparisons of means.

Table 7 shows the results for crossover frequencies, double crossover frequencies, and coincidence coefficients. Table 8 gives the results for strand and tetrad class frequencies. The $\mathrm{H} / \mathrm{C}$ ratios for crossover frequencies and coincidence coefficients are shown in fig. 5 .

It can be seen that the effect on crossover frequency of the $\mathrm{H} 3 \mathrm{rd}$ chromosome is highest for the most distal region (1) of the $\mathrm{X}$. A comparison of the logarithm of the $\mathrm{H} / \mathrm{C}$ ratio for region 1 with the mean $\log$ ratio for the rest of the $\mathrm{X}$ chromosome is highly significant $(z=4.33, p<0.001$ on a normal deviate test). Nevertheless, there is evidence for small but significant effects in regions 3 and 4 . 
Table $7 \mathrm{X}$ chromosome crossover frequencies, double crossover frequencies, and coincidence coefficients in females with $\mathrm{H}$ or $\mathrm{C}$ 3 rd chromosomes

\begin{tabular}{|c|c|c|c|c|c|c|}
\hline \multirow[b]{2}{*}{ Interval } & \multicolumn{3}{|c|}{ Single Crossover Frequencies } & & & \\
\hline & C Mean & H Mean & $t$ & & & \\
\hline 1 & $0 \cdot 163 \pm 0 \cdot 006$ & $0 \cdot 216 \pm 0.006$ & $6 \cdot 44 \ddagger$ & & & \\
\hline 2 & $0.248 \pm 0.007$ & $0 \cdot 256 \pm 0 \cdot 006$ & 0.88 & & & \\
\hline 3 & $0.269 \pm 0.006$ & $0 \cdot 286 \pm 0 \cdot 006$ & $2 \cdot 13^{*}$ & & & \\
\hline \multirow[t]{2}{*}{4} & $0 \cdot 110 \pm 0 \cdot 004$ & $0 \cdot 120 \pm 0.004$ & $2 \cdot 06^{*}$ & & & \\
\hline & \multicolumn{3}{|c|}{ Double Crossover Frequencies } & \multicolumn{3}{|c|}{ Coincidence Coefficients } \\
\hline Intervals & C: Mean & H Mean & $t$ & C Mean & H Mean & $t$ \\
\hline $1 / 2$ & $0.0186 \pm 0 \cdot 0022$ & $0.0283 \pm 0.0022$ & $3 \cdot 53+$ & $0.459 \pm 0.046$ & $0.512 \pm 0.033$ & 0.93 \\
\hline $2 / 3$ & $0 \cdot 0466 \pm 0 \cdot(0032$ & $0.0545 \pm 0.0032$ & $2 \cdot 27^{*}$ & $0.698 \pm 0.042$ & $0.743 \pm 0.036$ & 0.83 \\
\hline $3 / 4$ & $0.0307 \pm 0.0026$ & $0 \cdot 0290 \pm 0.0026$ & 0.94 & $1 \cdot 038+0.073$ & $0.841+0.063$ & $-2 \cdot 04^{*}$ \\
\hline
\end{tabular}

Each $t$ value has $229 \mathrm{df}$.

Table 8 Frequencies of different strand and tetrad classes for the $\mathrm{X}$ chromosome in females with $\mathrm{H}$ or $\mathrm{C} 3 \mathrm{rd}$ chromosomes

\begin{tabular}{|c|c|c|c|}
\hline \multirow{2}{*}{$\begin{array}{l}\text { No. of } \\
\text { Exchanges }\end{array}$} & \multicolumn{3}{|c|}{ Mean Frequencies } \\
\hline & $\mathrm{C}$ & $\mathrm{H}$ & $t$ \\
\hline \multicolumn{4}{|l|}{ Strands } \\
\hline 0 & $0.382 \pm 0.008$ & $0.335 \pm 0.005$ & $-5 \cdot 00+$ \\
\hline 1 & $0.458 \pm 0.008$ & $0.469 \pm 0.007$ & $1 \cdot 06$ \\
\hline 2 & $0 \cdot 146 \pm 0 \cdot 005$ & $0 \cdot 178 \pm 0 \cdot 005$ & $4 \cdot 44 \div$ \\
\hline 3 & $0 \cdot 013 \pm 0 \cdot 002$ & $0 \cdot 017 \pm 0 \cdot 002$ & $1 \cdot 94$ \\
\hline \multicolumn{4}{|l|}{ Tetrads } \\
\hline 0 & $0 \cdot 055 \pm 0 \cdot 015$ & $0 \cdot 028 \pm 0 \cdot 015$ & $-1 \cdot 25$ \\
\hline 1 & $0.414 \pm 0.032$ & $0.320 \pm 0.032$ & $-2 \cdot 09^{*}$ \\
\hline 2 & $0.429 \pm 0.027$ & $0.520 \pm 0.027$ & $2 \cdot 37^{*}$ \\
\hline 3 & $0 \cdot 101 \pm 0 \cdot 012$ & $0 \cdot 132 \pm 0 \cdot 012$ & $1 \cdot 83$ \\
\hline \multicolumn{4}{|c|}{ Mean Crossover Numbers } \\
\hline Strand & $0.788 \pm 0.012$ & $0.888 \pm 0.009$ & $6.06 \div$ \\
\hline Tetrad & $1.576 \pm 0.022$ & $1.755 \pm 0.022$ & $5.85 t$ \\
\hline
\end{tabular}

Despite the fact that double crossover frequencies are significantly elevated in $\mathrm{H}$ females, there is no evidence for any effect on coincidence coefficients, apart from a reduction of dubious significance in regions $3 / 4$. The tetrad analysis shows evidence for a significant reduction in the 1 exchange class frequency, and an increase in the 2 exchange frequency. The mean numbers of crossovers per strand and per tetrad are significantly increased in $H$ females.

\section{(iv) Effect of the 3rd chromosome on chromosome 2}

Females of the genotypes below were crossed to alsp males, and the progeny scored for the markers

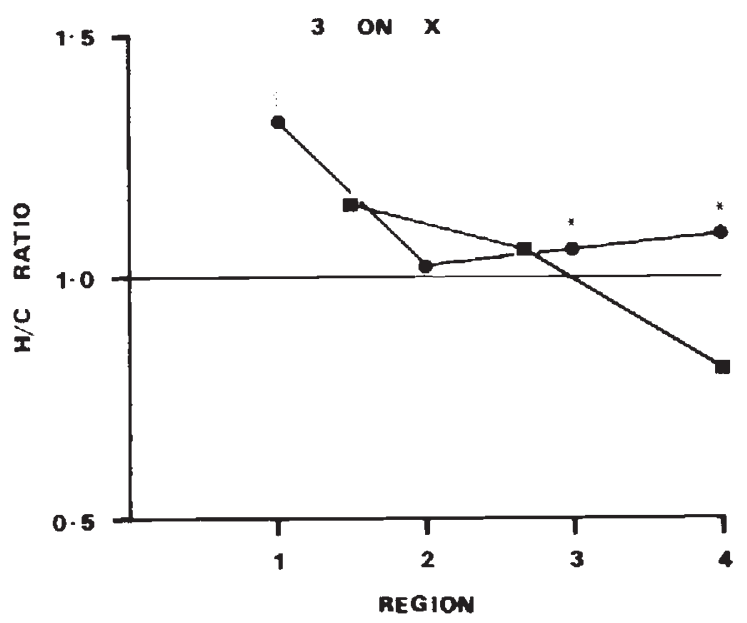

Figure 5 As for fig. 2, except that the effect is that of chromosome 3 on the $X$ chromosome.

shown in fig. 4 ( 3 on 2). ( $d p$ and $c n$ were omitted from the analysis, because of classification errors.)

$$
\begin{array}{rrr}
\mathrm{C}(T M 6): \frac{\mathrm{H}}{\mathrm{H}} \frac{\mathrm{H}}{\text { alsp }} \frac{T M 6}{G l_{\mathrm{C}}} & \mathrm{H}(T M 6): \frac{\mathrm{H}}{\mathrm{H}} \frac{\mathrm{H}}{\text { alsp }} \frac{T M 6}{G l_{\mathrm{H}}} \\
\mathrm{C}(S b): \frac{\mathrm{H}}{\mathrm{H}} \frac{\mathrm{H}}{\text { alsp }} \frac{S b_{\mathrm{H}}}{G l_{\mathrm{C}}} & \mathrm{H}(S b): \frac{\mathrm{H}}{\mathrm{H}} \frac{\mathrm{H}}{\text { alsp }} \frac{S b_{\mathrm{H}}}{G l_{\mathrm{H}}}
\end{array}
$$

The comparison between $\mathrm{H}$ and $\mathrm{C}$ females (either $T M 6$ or $S b$ ) provides a measure of the effect of the $G l_{\mathrm{H}} 3 \mathrm{rd}$ chromosome on recombination in flies heterozygous for the balancer TM6 or for the non-inverted $S b_{\mathrm{H}}$ chromosome, respectively. The experiments were carried out over four weekly blocks, involving $40 \mathrm{C}$ and $37 \mathrm{H}($ TM6) cultures (3379 and 3677 flies, respectively), and $39 \mathrm{C}$ and 
$41 \mathrm{H}(S b)$ cultures (4382 and 5011 flies, respectively). Block effects were significant in some cases, and were thus removed from the analyses. Table 9 shows the results for crossover frequencies, table 10 for double crossover frequencies and coincidence coefficients, and table 11 for tetrad and strand class frequencies. Fig. 6 displays the $\mathrm{H} / \mathrm{C}$ ratios for crossover frequencies and coincidence coefficients.

The data in table 9 suggest that the $\mathrm{H}$ 3rd chromosome decreases recombination in chromosome 2; two of the comparisons are significant at the $p<0.05$ level, and the chance of obtaining 7 out of 8 negative deviations is 0.035 on the null hypothesis. Table 11 shows that the mean numbers of crossovers per strand or tetrad are significantly decreased in $\mathrm{H}($ TM6) females; the decrease in number per strand borders on significance in the $S b$ females. There is no evidence for a consistent

Table 9 Chromosome 2 crossover frequencies of females with $\mathrm{H}$ or $\mathrm{C} 3 \mathrm{rd}$ chromosomes

\begin{tabular}{llll}
\hline Interval & C Mean & H Mean & $t$ \\
\hline TM6 & & & \\
Females & & & \\
1 & $0.448 \pm 0.010$ & $0.423 \pm 0.010$ & 1.77 \\
2 & $0.103 \pm 0.007$ & $0.077 \pm 0.007$ & $2.02^{*}$ \\
3 & $0.428 \pm 0.011$ & $0.425 \pm 0.011$ & 0.18 \\
4 & $0.085 \pm 0.006$ & $0.084 \pm 0.006$ & 0.21 \\
\hline
\end{tabular}

The $t$ values each have $69 \mathrm{df}$.

\begin{tabular}{llll}
\hline Sb & & & \\
Females & & & \\
1 & $0.397 \pm 0.010$ & $0.386 \pm 0.010$ & 0.78 \\
2 & $0.095 \pm 0.007$ & $0.068 \pm 0.007$ & $2.28^{*}$ \\
3 & $0.375 \pm 0.009$ & $0.386 \pm 0.009$ & 0.89 \\
4 & $0.088 \pm 0.005$ & $0.081 \pm 0.005$ & 0.69 \\
\hline
\end{tabular}

The $t$ values each have $72 \mathrm{df}$. effect on coincidence coefficients. There is a significant decrease in 3 exchange strand frequency in $\mathrm{H}$ (TM6) females, a highly significant decrease in 2 exchange strand frequency in $\mathrm{H}(S b)$ females, and a significant increase in 1 exchange tetrad frequency in $\mathrm{H}(S b)$ females.

\section{GENETIC EFFECTS ON NON-DISJUNCTION}

\section{(i) X chromosome non-disjunction}

Females of various genotypes were crossed to FM7 males and their female offspring scored for XXY exceptions, as described in section 2(ii). The results are shown in table 12. A contingency $\chi^{2}$ test shows no significant difference between $C y$ and $C y^{+}$ females, so that these can be pooled. The frequency of non-disjunction is significantly lower in females with all $\mathrm{H}$ chromosomes $\left(7 \cdot 29 \times 10^{-4}\right.$ compared with $14.92 \times 10^{-4}, \chi_{1}^{2}=4.95, p<0.02$ on a onetailed test).

\section{(ii) Chromosome 3 non-disjunction}

Females of various genotypes were crossed to $\mathrm{C}(3 L), \mathrm{C}(3 R)$ males, and the numbers of exceptional (i.e., viable) offspring in their progeny counted. Control measurements of numbers of offspring of these genotype were also carried out (section 2 (ii)). The results are shown in table 13 , where the numbers of bottles with $0,1,2$, and 3 exceptions are shown for each genotype, together with means and standard errors of the productivity of the control crosses. The distributions of exceptions per culture for each genotype were tested for agreement with the Poisson distribution; none of the genotypes shows a significant departure from Poisson expectation. The mean frequency of

Table 10 Chromosome 2 double crossover frequencies and coincidence coefficients of females with $\mathrm{H}$ or $\mathrm{C} 3$ rd chromosomes

\begin{tabular}{|c|c|c|c|c|c|c|}
\hline \multirow[b]{2}{*}{ Intervals } & \multicolumn{3}{|c|}{ Double Crossover Frequencies } & \multicolumn{3}{|c|}{ Coincidence Coefficients } \\
\hline & C Mean & H Mean & $t$ & C Mean & H Mean & $t$ \\
\hline \multicolumn{7}{|l|}{$\begin{array}{l}\text { TM6 } \\
\text { Females }\end{array}$} \\
\hline $1 / 2$ & $0.0395 \pm 0.0039$ & $0.0260 \pm 0.0039$ & 1.99 & $0.860 \pm 0.048$ & $0 \cdot 802 \pm 0.071$ & -0.67 \\
\hline $2 / 3$ & $0.0447 \pm 0.0049$ & $0.0318 \pm 0.0468$ & $1 \cdot 52$ & $1 \cdot 016 \pm 0.057$ & $0.974 \pm 0 \cdot 079$ & -0.43 \\
\hline $3 / 4$ & $0 \cdot 0296 \pm 0.0033$ & $0 \cdot 0280 \pm 0.0033$ & $0 \cdot 18$ & $0.814 \pm 0.072$ & $0.781 \pm 0.073$ & $-0 \cdot 32$ \\
\hline \multicolumn{7}{|l|}{$\begin{array}{l}S b \\
\text { Females }\end{array}$} \\
\hline $1 / 2$ & $0.0255 \pm 0.0034$ & $0.0193 \pm 0.0034$ & $0 \cdot 97$ & $0.676 \pm 0.070$ & $0.733 \pm 0.102$ & $0 \cdot 46$ \\
\hline $2 / 3$ & $0.0413 \pm 0.0056$ & $0.0232 \pm 0.0056$ & $2 \cdot 73 \dagger$ & $1 \cdot 163 \pm 0 \cdot 098$ & $0.877 \pm 0.145$ & $-1 \cdot 64$ \\
\hline $3 / 4$ & $0.0217 \pm 0.0030$ & $0 \cdot 0220 \pm 0.0030$ & $0 \cdot 16$ & $0.655 \pm 0.077$ & $0.701 \pm 0.082$ & $0 \cdot 41$ \\
\hline
\end{tabular}


Table 11 Frequencies of different strand and tetrad classes for chromosome 2 in females with $\mathrm{H}$ or $\mathrm{C} 3$ rd chromosomes

\begin{tabular}{|c|c|c|c|c|c|c|}
\hline \multirow{2}{*}{$\begin{array}{l}\text { No. of } \\
\text { Exchanges }\end{array}$} & \multicolumn{2}{|c|}{ Strand Frequencies } & \multicolumn{3}{|c|}{ Tetrad Frequencies } & \multirow[b]{2}{*}{$t$} \\
\hline & C Mean & H Mean & $t$ & C Mean & H Mean & \\
\hline \multicolumn{7}{|l|}{$T M 6$} \\
\hline \multicolumn{7}{|l|}{ Females } \\
\hline 0 & $0 \cdot 248 \pm 0.010$ & $0.268 \pm 0.009$ & $1 \cdot 54$ & $-0 \cdot 006 \pm 0 \cdot(020$ & $-0.010+0.020$ & $-0 \cdot 15$ \\
\hline 1 & $0.467 \pm 0.010$ & $0.478 \pm 0.011$ & 0.74 & $0 \cdot 164 \pm 0.053$ & $0.218+0.053$ & 0.72 \\
\hline 2 & $0.246+0.010$ & $0 \cdot 226 \pm 0 \cdot 010$ & $-1 \cdot 38$ & $0.552+0.058$ & $0.578 \pm 0.058$ & 0.32 \\
\hline 3 & $0.037 \pm 0.005$ & $0.026 \pm 0.003$ & $-2 \cdot 06^{*}$ & $0 \cdot 288 \cdot 2 \cdot 0 \cdot 031$ & $0 \cdot 212 \pm 0 \cdot 031$ & $-1 \cdot 72$ \\
\hline \\
\hline \multicolumn{7}{|l|}{ Females } \\
\hline 0 & $0.290+0.010$ & $0 \cdot 309 \pm 0 \cdot 008$ & 1.57 & $0.015+0.016$ & $0 \cdot 004 \pm 0 \cdot 016$ & -0.49 \\
\hline 1 & $0.469 \pm 0.010$ & $0.477 \pm 0.006$ & 0.65 & $0 \cdot 216+0.038$ & $0.328 \pm 0.038$ & $2.05^{*}$ \\
\hline 2 & $0 \cdot 216 \pm 0 \cdot 007$ & $0 \cdot 191 \pm 0 \cdot 006$ & $-2 \cdot 74 t$ & $0.616 \pm 0.049$ & $0 \cdot 491 \pm 0 \cdot(049$ & -1.79 \\
\hline 3 & $0.228 \pm 0.004$ & $0 \cdot 225 \pm 0 \cdot 003$ & -0.06 & $0 \cdot 152 \pm 0 \cdot 016$ & $0.177 \pm 0.016$ & $-1 \cdot 45$ \\
\hline \multirow{2}{*}{$\begin{array}{l}\text { Mean } \\
\text { Crossover } \\
\text { Numbers* }\end{array}$} & \multicolumn{3}{|l|}{ Strands } & \multicolumn{3}{|l|}{ Tetrads } \\
\hline & C Mean & H Mean & $t$ & C. Mean & H Mean & $t$ \\
\hline TM6 & $1 \cdot 071 \pm 0 \cdot 022$ & $1 \cdot 009 \pm 0 \cdot 016$ & $2 \cdot 28 *$ & $2 \cdot 132 \pm 0.038$ & $2 \cdot 012 \pm 0 \cdot 038$ & $-2 \cdot 27^{*}$ \\
\hline$S b$ & $0.971 \pm 0.018$ & $0.926+0.015$ & -1.95 & $1.904 \pm 0.031$ & $1 \cdot 840 \pm 0 \cdot(031$ & -1.45 \\
\hline
\end{tabular}

exceptional offspring per culture can thus be calculated by assuming that multiple exceptionals are the product of independent events, and the frequency of exceptions per progeny individual can be estimated by dividing the frequency per culture by the mean number of flies per culture in the corresponding control. (Since the means for the genotypes other than $\mathrm{H} / \mathrm{H} \mathrm{Cy} / \mathrm{H} \mathrm{Gl} / \mathrm{H} b_{\mathrm{H}}$ do not differ, their joint mean was used as the estimate of the number of flies per culture for these genotypes.)

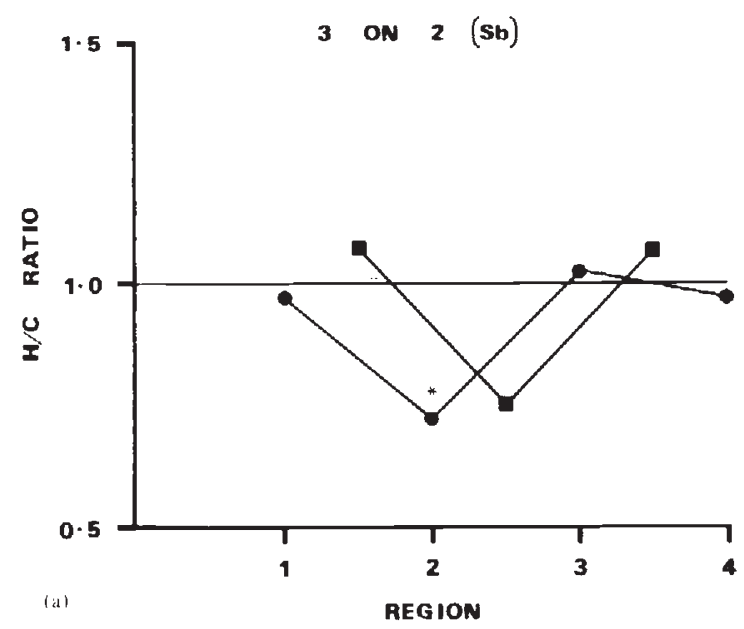

Figure 6(a) As for fig. 2, except that the effect is that of chromosome 3 on the 2 nd chromosome.

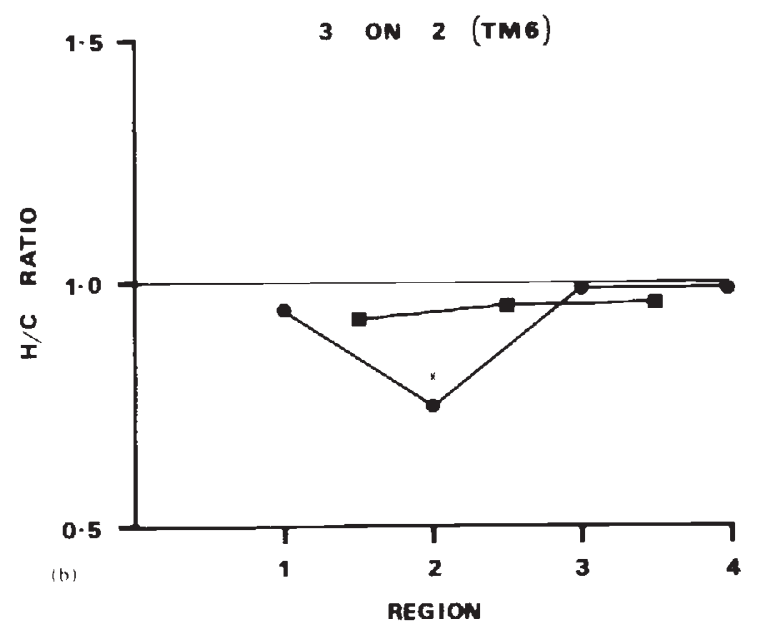

Figure $6(\mathrm{~b})$.

The estimated frequencies of exceptions are shown in table 13. It is clear that the frequency of exceptions is significantly higher among the progeny of $C y$ mothers than $C y^{+}$mothers, but that the $C$ vs. $H$ contrast has no significant effect. The full interpretation of these data depends on knowledge of the mechanism of non-disjunction. Some limited conclusions about this can be drawn from the distribution of phenotypes among the exceptional individuals, shown in the lower part of table 13. If non-disjunction occurred exclusively at the first meiotic division, then all the diplo- 3 products of non-exchange tetrads (with respect to crossovers 
Table $12 \mathrm{X}$ chromosome non-disjunction in females

\begin{tabular}{llll}
\hline $\begin{array}{l}\text { Genotype of } \\
\text { Female }\end{array}$ & $\begin{array}{l}\text { Regular } \\
\text { Female } \\
\text { Offspring }\end{array}$ & $\begin{array}{l}\text { Exceptional } \\
\text { Female } \\
\text { Offspring }\end{array}$ & $\begin{array}{l}\text { Frequency } \\
\text { of Non- } \\
\text { disjunction } \\
\left(\times 10^{-4}\right)\end{array}$ \\
\hline $\mathrm{C} \frac{\mathrm{C}}{\mathrm{C}} \frac{G l_{\mathrm{C}}}{S b_{\mathrm{C}}}$ & 20,065 & 18 & $17.93 \pm 3.00$ \\
$\frac{\mathrm{C}}{\mathrm{C}} \frac{\mathrm{C}}{\mathrm{C}} \frac{G l_{\mathrm{C}}}{S b_{\mathrm{C}}}$ & 16,098 & 9 & $11 \cdot 18 \pm 2.63$ \\
$\frac{\mathrm{H}}{\mathrm{H}} \frac{G l_{\mathrm{H}}}{\mathrm{H}}$ & 16,292 & 4 & $4.91 \pm 1.74$ \\
$\frac{\mathrm{H}}{\mathrm{H}} \frac{C y}{\mathrm{H}} \frac{G l_{\mathrm{H}}}{S b_{\mathrm{H}}}$ & 22,120 & 10 & $9.04 \pm 2.02$ \\
\hline
\end{tabular}

in the interval $G l-S b$ ) would be $G l S b$ in phenotype. Single or double exchange tetrads would produce one-half $\mathrm{Gl} S \mathrm{~S}$ diplo-3 gametes and one-quarter lethal diplo-3 gametes. Hence, the frequency of $G l S b$ among non-wild type progeny is expected to be

$$
\begin{aligned}
a & =\left\{\frac{1}{2} \times \frac{3}{4} z+(1-z)\right\} /\left\{\frac{3}{4} z+1-z\right\} \\
& =\left(1-\frac{5}{8} z\right) /\left(1-\frac{1}{4} z\right)
\end{aligned}
$$

where $z$ is the frequency of exchange tetrads. Rearranging, we can estimate $z$ as

$$
\hat{z}=8(1-a) /(5-2 a) \text {. }
$$

The observed frequencies of $\mathrm{Gl} S \mathrm{~S}$ can be compared with those expected if non-disjunction products were obtained randomly from exchange and non-exchange tetrads at the first division. Neglecting multiple exchanges, the frequencies of exchange tetrads are twice the $G l-S b$ recombination frequencies, so that an overestimate of $z\left(z^{*}\right)$ is obtained by using the previously estimated recombination values for the four maternal genotypes (Charlesworth and Charlesworth, $1985 b)$. The corresponding values of $a\left(a^{*}\right)$ are

\begin{tabular}{|c|c|c|c|c|c|}
\hline $\begin{array}{l}\text { Maternal } \\
\text { Genotype }\end{array}$ & $a$ & $a^{*}$ & $\hat{z}$ & $z^{*}$ & $\begin{array}{c}\text { Number } \\
\text { Scored }\end{array}$ \\
\hline $\mathrm{C}$ & 0.833 & 0.913 & 0.401 & 0.220 & 12 \\
\hline $\mathrm{C} C y$ & 0.071 & 0.870 & 1.530 & 0.320 & 14 \\
\hline $\mathrm{H}$ & 0.556 & 0.833 & 0.914 & 0.400 & 9 \\
\hline $\mathrm{H} C y$ & 0.333 & 0.786 & $1 \cdot 231$ & 0.500 & 18 \\
\hline
\end{tabular}
easily found from the above formula. The results of these calculations are as follows:

Among the diplo-3 gametes of $C y$ mothers, it is clear that there is a considerable deficit of $\mathrm{Gl} S b$ over what would be expected if they were drawn at random from the pool of tetrads at first division: this deficiency is highly significant statistically $(p<$ $0 \cdot 001)$. Although the deficiency is non-significant for the $C y^{+}$mothers, there is a trend in the same

\begin{tabular}{|c|c|c|c|c|c|c|}
\hline \multirow{2}{*}{$\begin{array}{l}\text { Maternal } \\
\text { Genotype }\end{array}$} & \multirow{2}{*}{$\begin{array}{l}\text { Mean No. } \\
\text { Flies per Culture } \\
\text { (Controls) }\end{array}$} & \multicolumn{4}{|c|}{$\begin{array}{l}\text { Distribution of No's } \\
\text { Exceptionals per Culture }\end{array}$} & \multirow{2}{*}{$\begin{array}{l}\text { Frequencies of } \\
\text { Exceptionals } \\
\left(\times 10^{-4}\right)\end{array}$} \\
\hline & & 0 & 1 & 2 & 3 & \\
\hline$\frac{\mathrm{C}}{\mathrm{C}} \frac{\mathrm{C}}{\mathrm{C}} \frac{G l_{\mathrm{C}}}{S b_{\mathrm{C}}}$ & $474 \cdot 6 \pm 27 \cdot 1$ & 147 & 16 & 2 & 0 & $2 \cdot 53 \pm 0.56$ \\
\hline$\frac{\mathrm{C}}{\mathrm{C}} \frac{C y}{\mathrm{C}} \frac{G l_{\mathrm{C}}}{S b_{\mathrm{C}}}$ & $477 \cdot 1 \pm 26 \cdot 7$ & 104 & 16 & 2 & 2 & $4 \cdot 37 \pm 0 \cdot 86$ \\
\hline$\frac{\mathrm{H}}{\mathrm{H}} \frac{\mathrm{H}}{\mathrm{H}} \frac{G l_{\mathrm{H}}}{S b_{\mathrm{H}}}$ & $486 \cdot 6 \pm 26 \cdot 6$ & 145 & 11 & 2 & 0 & $1.98 \pm 0.51$ \\
\hline$\frac{\mathrm{H}}{\mathrm{H}} \frac{C y}{\mathrm{H}} \frac{G l_{\mathrm{H}}}{S b_{\mathrm{H}}}$ & $562 \cdot 0 \pm 29 \cdot 7$ & 98 & 17 & 4 & 1 & $4 \cdot 15 \pm 0.78$ \\
\hline
\end{tabular}
direction.

Table 13 Chromosome 3 non-disjunction in females

Distribution of exceptional individuals

\begin{tabular}{lccccc}
\cline { 2 - 5 } & $G l+$ & $S b+$ & $G l S b$ & ++ & Total \\
\hline$\frac{\mathrm{C}}{\mathrm{C}} \frac{\mathrm{C}}{\mathrm{C}} \frac{G l_{\mathrm{C}}}{S b_{\mathrm{C}}}$ & 1 & 1 & 11 & 7 & 20 \\
$\mathrm{C} \frac{C y}{\mathrm{C}} \frac{G l_{\mathrm{C}}}{S b_{\mathrm{C}}}$ & 6 & 7 & 1 & 12 & 26 \\
$\frac{\mathrm{H}}{\mathrm{H}} \frac{\mathrm{H}}{\mathrm{H}} \frac{G l_{\mathrm{H}}}{S b_{\mathrm{H}}}$ & 3 & 1 & 5 & 5 & 14 \\
$\frac{\mathrm{H}}{\mathrm{H}} \frac{G l_{\mathrm{H}}}{\mathrm{H}}$ & 9 & 3 & 6 & 10 & 28 \\
\hline
\end{tabular}


There are two possible interpretations of these results. One is that non-disjunction occurs solely at first division, and that non-disjunctional gametes are produced predominantly from tetrads with exchanges in the $\mathrm{Gl}-\mathrm{S} b$ region (Charlesworth and Charlesworth, 1958b). The difficulty with this is that there is a deficiency of $G l S b$ compared with the frequency expected if all diplo-3 gametes were derived from exchange tetrads, as can be seen for the $C y$ mothers, whose $\hat{z}$ values exceed one. This could be due to a viability disadvantage of $G l S b$ individuals.

The alternative is to suppose that non-disjunction occurs at least partly at the second meiotic division. If this is the case, then, since only exchange products between $G l$ and the centromere and/or $S b$ and the centromere are viable products of second division non-disjunction, the deficiency of $G l S b$ and the increased frequency of exceptionals among the progeny of $C y$ individuals are explicable.

The frequencies of nullo-3 gametes produced by non-disjunction at either meiotic division are equal to the frequencies of wild-type progeny. These are as follows:

Maternal Genotype
C
C Cy
$\mathrm{H}$
$\mathrm{H} C y$

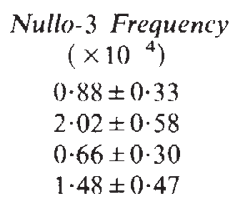

It is clear that the frequency of nullo-3's is much higher in the gametes of $C y$ mothers than $C y^{\prime}$ mothers, but that other effects are non-significant, although the high recombination genotypes have somewhat lower frequencies of nullo-3's.

\section{DISCUSSION}

\section{(i) Regional specificity results}

Our results, and those of other studies of quantitative effects on recombination in $D$. melanogaster (Chinnici, 1971; Kidwell, 1972; Brooks and Marks, 1985), show a considerable diversity of pattern of regional effects on crossing over. The $\mathrm{H} \mathrm{X}$ chromosome appears to affect crossing over more or less uniformly along chromosome 3 , with no consistent effect on coincidence (fig. 2); our previous work (Charlesworth and Charlesworth, 1985a,b) suggests that the $\mathrm{H} / \mathrm{C} \mathrm{X}$ chromosome difference is due to a single gene or tightly-linked group of genes. This effect is reminiscent of that of the sex-linked meiotic mutant mei-9, which reduces recombination uniformly on all major chromosomes, and has no effect on coincidence (Carpenter and Sandler, 1974). Unfortunately, we have no data at present on the effect of the $\mathrm{H} \mathrm{X}$ chromosome on chromosomes other than 3 , nor on its possible allelism with mei-9, but it is tempting to speculate that the gene concerned is responsible for a generalised increase in crossover frequency.

The $\mathrm{H}$ chromosome 3 appears to increase $\mathrm{X}$ and 3 rd chromosome crossover frequencies in regions where crossover frequency per unit DNA is normally low (cf. Lindsley and Sandler, 1977); its effect is most marked on the centromeric region of 3 (fig. 3) and the telomeric region of the $X$ (fig. 5). It also increases coincidence coefficients on 3 , but apparently not on the $\mathrm{X}$, although the statistical reliability of the $X$ coincidence coefficients is not high enough to rule out an effect in the telomeric region. This kind of regional specificity has been reported previously for quantitative effects by Chinnici (1971) and Kidwell (1972), and is the common pattern for meiotic mutants (Baker and Hall, 1976; Lindsley and Sandler, 1977; Szauter, 1984). It is consistent with the idea that normal regional constraints on crossing over are being disrupted by the genes concerned, in this case by genes which increase rather than decrease crossing over (cf. Baker and Carpenter, 1972; Lindsley and Sandler, 1977; Szauter, 1984).

In this respect, the properties of the chromosome $3 \mathrm{H}$ genes are similar to those of most meiotic mutants affecting exchange processes. They differ sharply, however, in that there is good evidence that the chromosome $3 \mathrm{H}$ genes reduce crossing over in chromosome 2, whereas the meiotic mutants nearly all have similar effects on all chromosomes (Baker and Hall, 1976). The effect on chromosome 2 is most marked for the centromeric region (fig. 6), as might be expected from the specificity pattern for the $\mathrm{X}$ and 3 rd chromosomes described above. Those data suggest that, in addition to the well-established within-chromosome regional constraints on exchange frequency (Szauter, 1984), there are chromosome-specific factors affecting exchange. That there is a potential antagonism between crossover frequencies on chromosomes 2 and 3 is further suggested by the data of table 2 of Charlesworth and Charlesworth $(1985 b)$, which show that the $\mathrm{H}$ chromosome 2 decreases crossing over between the 3rd chromosome genes $G l$ and $S b$ unless the $\mathrm{X}$ and 3rd chromosomes are both $\mathrm{H}$ in constitution. Chinnici's (1971) data also suggest some interchromosomal effects of this sort. It is clear, 
however, that they are not of the same class as the classic inter-chromosomal effects of inversion heterozygosity, since these are not chromosomespecific in the same way as our effects, and are also associated with increases in coincidence as well as crossing over (Lucchesi, 1976). Such interchromosomal antagonism is not the rule, however; Brooks and Marks (1985) report a generally positive correlation between effects on different chromosomes of minor genes carried on chromosomes extracted from natural populations.

\section{(ii) Evolutionary implications of the regional specificity results}

The results surveyed above show clearly that recombination modifier genes can influence crossover frequencies in neighbouring parts of the chromosome; mapping experiments (Charlesworth and Charlesworth, 1985b) demonstrated the existence of a pair of high recombination genes on chromosome 3 , one located between $h$ and $G l$ at approximately 30 , the other either between $s t$ and $s r$ or to the right of $s r$ at approximately 53 . Reference to figs. 1 and 3 shows that these are localities in which crossover frequencies are significantly affected by the $\mathrm{H} 3 \mathrm{rd}$ chromosome. The requirement of close linkage between recombination modifier genes and the regions they affect for effective natural selection on recombination (Nei, 1967; 1969; Maynard Smith, 1978) is thus met in this case.

But it is equally clear that recombination may be affected by genes on other chromosomes or located some distance away on the same chromosome, e.g., there is a significant effect of the chromosome $3 \mathrm{H}$ genes on crossing over at the distal end of $3 R$, on the distal and proximal ends of the X, and on the proximal region of $2 L$ (figs. $3,5,6)$. Inter-chromosome and inter-region effects have also been observed in other Drosophila studies of quantitative effects on recombination (Chinnici, 1971; Brooks and Marks, 1985), and in other organisms such as Neurospora (Catcheside, 1977) and the silkworm (Turner, 1979; Ebinuma and Yoshitake, 1981). They imply that natural selection for or against crossing over in one region may have correlated effects on crossing over elsewhere in the genome; these correlations may be positive or negative, depending on the genes and chromosomal regions concerned. Furthermore, unless there happen to be recombination modifiers that are closely linked to the regions experiencing such correlated responses, it may be difficult for selection to reverse them.
These effects clearly make it difficult, if not impossible, to interpret data on interspecies differences in recombination rates in terms of selective hypotheses. The evidence from the comparisons of genetic maps in the genus Drosophila suggests that differences in crossover frequencies are usually of similar magnitude over all chromosomes e.g., the comparison of the D. melanogaster map with that of $D$. subobscura (Loukas et al., 1979) and D. pseudoobscura (Dobzansky and Powell, 1975 ), or with $D$. virilis (Alexander, 1976). It is not clear whether this reflects adjustment of the overall frequency of genetic recombination to different selective conditions, or a correlated response to selection on a much more limited part of the genome. Similarly, the simplest interpretation of the lack of crossing over in the heterogametic sex of many insect species (White, 1973 , pp. 469-490) is that it represents the response to selection for restricting recombination between the sex chromosomes (Nei, 1969; Charlesworth and Charlesworth, 1980; Bull, 1983).

\section{(iii) Effects on non-disjunction}

A higher frequency of crossing over must usually lead to a reduced frequency of non-exchange tetrads, and hence a reduced frequency of nondisjunction. Our data on the effects of the high recombination genes on $\mathrm{X}$ and $3 \mathrm{rd}$ chromosome non-disjunction gave conflicting results. There was a 2-fold reduction in the frequency of $X$ nondisjunction in $\mathrm{H}$ compared with $\mathrm{C}$ females (table 12 ), whereas there is only a small and statistically non-significant effect on 3rd chromosome nondisjunction (table 13). It is interesting to note that table 8 shows a roughly 2 -fold reduction in the frequency of $\mathrm{X}$ chromosome non-exchange tetrads when an $\mathrm{H}$ chromosome 3 is substituted for $\mathrm{C}$ (although this effect is not significant), whereas tables 3 and 6 reveal no effects on 3rd chromosome non-exchange tetrads of the substitution of $\mathrm{H}$ for $\mathrm{C} \mathrm{X}$ or $3 \mathrm{rd}$ chromosomes. (None of the 3rd chromosome non-exchange frequencies differ significantly from zero, presumably because of the greater map length of the metacentric chromosome 3.) Reduction in single exchange frequencies are noticeable for both $\mathrm{X}$ and 3rd chromosomes, however.

Tables 12 and 13 show that heterozygosity for the multiply-inverted 2 nd chromosome $S M 1(C y)$ has no detectable effect on $\mathrm{X}$ chromosome nondisjunction, but causes a more than two-fold increase in the frequency of nullo- 3 gametes. (The frequency of diplo-3 gametes cannot be reliably 
estimated, as described in section 4(ii).) Cooper et al. (1955) and Roberts (1962) have previously reported a lack of effect of autosomal inversion heterozygosity on the rate of non-disjunction of structurally homozygous $\mathrm{X}$ chromosomes (in the absence of a Y), and Ramel (1962) has reported an increased rate of autosomal non-disjunction in response to inversion heterozygosity on the other chromosomes. Our results are, therefore, in good agreement with earlier findings.

The reason for the difference in response of the $\mathrm{X}$ and autosomes to inversion heterozygosity on non-homologues, however, is unclear, As discussed earlier (section 4(ii)), it is possible that our data on the genotypes of diplo-3 gametes can be explained by an association between first division non-disjunction and exchange in the $\mathrm{Gl}-\mathrm{S} b$ region. No such association between proximal exchange and primary non-disjunction of the $\mathrm{X}$ chromosome was detected by Merriam and Frost (1964), so that it is possible that the increase in frequency of crossing over on the $\mathrm{X}$ and chromosome 3 due to the presence of $S M 1$ will only affect chromosome 3 non-disjunction. Evidence for an association between first division non-disjunction and proximal exchange has been reported for Ustilago violacea by Cattrall et al. (1978). There is a similar relationship between proximal gene conversion and chromosome loss in disomics of yeast (Campbell and Fogel, 1977; Campbell, 1980), so that this explanation has some plausibility. The alternative explanation of our data on diplo-3 gametes requires a substantial contribution of second division non-disjunction to the events we detect. The available data for the $\mathrm{X}$ chromosome suggest strongly that second division non-disjunction is rare, if not absent (Merriam and Frost, 1964), so that the mechanism of autosomal nondisjunction would have to be radically different. It also provides no explanation for the effects of $S M 1$. Further genetic experiments are necessary to settle this question. Whatever the final interpretation, it seem clear that chromosome 3 nondisjunction frequently involves exchange tetrads under normal conditions, as is true also for the $\mathrm{X}$ (Merriam and Frost, 1964).

\section{(iv) Evolutionary implications of the non-disjunction results}

These data provide some support for the idea that increased rates of crossing over may be favoured due to a concomitant reduction in non-disjunction frequency (cf. Darlington, 1958, Chaps. 15, 24). However, the selective impact of such an effect is small, since autosomal non-disjunction is unaffected and the reduction in $\mathrm{X}$ chromosome nondisjunction frequency is of the order of $0.5 \times 10^{-3}$, which represents approximately twice the selective advantage accruing from the reduction in frequency of metafemale and YO male progeny. Furthermore, as pointed out by White (1973, pp. 169-170) and Maynard Smith (1978, pp. 72-73), the localisation of chiasmata and other such devices provide means of ensuring tetrads with single exchanges per bivalent but effectively zero recombination between most genes on the same chromosome. It thus seem unlikely that the prevention of non-disjunction can be a major force in maintaining non-zero frequencies of exchange, although the well-documented increase in nondisjunction frequency caused by meiotic mutants with drastic, generalised effects on crossover rates (Baker and Hall, 1976) must help to prevent their spread in natural populations. As pointed out to us by Dr Janice Spofford, the selective impact of non-disjunction may be greater in Drosophila species with all acrocentric autosomes (see above). This might explain why species such as $D$. virilis and $D$. subobscura have high rates of recombination compared with $D$. melanogaster. Lower levels of interference might also be favoured in such species, since more even spacing of exchanges reduces the frequency of non-exchange tetrads.

Acknowledgements This work was supported by a grant from the Nuffield Foundation. We thank Martyn Stenning, Joan West, and Doris Williams for technical assistance, and Lisa Brooks for showing us her unpublished work with William Marks. Charles Langley and Janice Spofford made suggestions for improving the manuscript.

\section{REFERENCES}

ALEXANI)IR, M. 1.. 1976. The genetics of Drosophila virilis. In Ashburner, M. and Novitski, E. (eds.), The Genetics and Biology of Drosophila Vol. 1c, Academic Press, New York, pp. 1365-1627.

BAKER, B. S., ANI) (:ARPENTER, A. T. C. 1972. Genetic analysis of sex chromosomal meiotic mutants in Drosophila melanogaster. Genetics, 71, 225-286.

BAKER, B. S., AND HALL, J. C. 1976. Meiotic mutants: genic control of meiotic recomination and chromosome segregation. In Ashburner, M. and Novitski, E. (eds.) The Genetics and Biology of Drosophila. Vol. la, Academic Press, New York, pp. 351-434.

BIRD, J. M. 1946. X chromosome of D. subobscura. Drosophila Information Service 20: 84.

BIRD, J. M. 1947. Additional notes on the X chromosome of $D$. subobscura. Drosophila Information Service 21: 83

BROOKS, L. 1), ANI) MARKS, R. W. 1985. The organization of genetic variation for recombination in Drosophila melanogaster. Genetics (submitted) 
BULL, J. J. 1983. Evolution of Sex-Determining Mechanisms. Benjamin Cummings, Menlo Park.

CARPENTER, A. T. C., AND SANDLER, L. 1974. On recombination-defective meiotic mutants in Drosophila melanogaster. Genetics, 76, 453-475.

CATCHESIDE, D. G. 1977. The Genetics of Recombination. Arnold, London.

CAMPBELL, D. 1977. Association of disomic chromosome loss with EMS-induced conversion in yeast. Genetics, 96, 613625 .

CAMPBELl, D., AND FOGEL, S. 1980. Association of chromosome loss with centromere-adjacent recombination in a yeast disomic haploid. Genetics, 85, 573-585.

CATTRALL, M. E., BAIRD, M. L. AND GARBER, E. D. 1978. Genetics of Ustilago violacea. III. Crossing over and nondisjunction. Bot. Gaz., 139, 266-270.

CHARLESWORTH, B., AND CH ARLESWORTH, D. $1985 a$. Genetic variation in recombination in Drosophila. I. Responses to selection and preliminary genetic analysis. Heredity, 54, 71-84.

CHARLESWORTH, B., AND CHARLESWORTH, D. 1985b. Genetic variation in recombination in Drosophila. II. Genetic analysis of a high recombination stock. Heredity, 54 85-98.

CHARLESWORTH, D., AND CHARLESWORTH, B. 1980. Sex differences in fitness and selection for centric fusions between sex chromosomes and autosomes. Genet. Res., 35, $205-216$.

CHINNICI, J. P. 1971. Modification of recombination frequency in Drosophila. II. The polygenic control of crossing over. Genetics, 69, 85-96.

COOPER, K. W., ZIMMERING, S. AND KRIVSHENKO, J. 1955. Interchromosomal effects and segregation. Proc. Nat. Acad. Sci. USA, 41, 911-914.

DARLINGTON, C. D. 1958. The Evolution of Genetic Systems. (2nd edn.). Oliver and Boyd, Edinburgh.

DOBZHANSKY, T., AND POWELl, J. R. 1975. Drosophila pseudoobscura and its American relatives $D$. persimilis and D. miranda. In King, R. C. (ed.), Handbook of Genetics. Vol. 3. Invertebrates of Genetic Interest, pp. 537-587.

EBINUMA, H., AND YOSHITAKE, N. 1981. The genetic system controlling recombination in the silkworm. Genetics, 99, 231-245.

GRELl, R. F. 1976. Distributive pairing. In Ashburner, M. and Novitski, E. (eds.), The Genetics and Biology of Drosophila. Vol. 1a, Academic Press, New York, pp. 435-486.

HOLM, D. G. 1976. Compound autosomes. In Ashburner, M. and Novitski, E. (eds.), The Genetics and Biology of Drosophila. Vol. 1b, Academic Press, New York, pp. 529561.
KIDWELL, M. G. 1972. Genetic change of recombination value in Drosophila melanogaster. I. Artificial selection for high and low recombination and some properties of recombination-modifying genes. Genetics, 70, 419-432.

KOSKE, T., AND MAYNARD SMITH, J. 1954. Genetics and cytology of Drosophila subobscura. X. The fifth linkage group. J. Genet., 52, 521-541.

LINDSLEY, D. L., AND SANDL.ER, L. 1977. The genetic analysis of meiosis in female Drosophila melanogaster. Phil. Trans. Roy. Soc. Lond. B., 277, 295-312.

LOUKAS, M., KRIMBAS, C. B., MAVRAGANI-TSIPIDOU, P., AND KASTRITSIS, C. D. 1979. The genetics of allozyme loci in Drosophila subobscura, and its photographic chromosome map. J. Hered., 70, 17-26.

LUCCHESI, J. C. 1976. Inter-chromosomal effects. In Ashburner, M. and Novitski, E. (eds.), The Genetics and Biology of Drosophila. Vol. 1a., Academic Press, New York, pp. 315328.

MAYNARD SMITH, J. 1978. The Evolution of Sex. Cambridge University Press, London.

MERRIAM, J. R., AND FROST, J. N. 1964. Exchange and nondisjunction of the $\mathrm{X}$ chromosomes in female Drosophila melanogaster. Genetics, 49, 109-122.

NEI, M. 1967. Modification of linkage intensity by natural selection Genetics, 57, 625-641.

NEI, M. 1969. Linkage modification and sex difference in recombination. Genetics, 63, 681-699.

RAMEL, C. 1962. Interchromosomal effect of inversions in Drosophila melanogaster. II. Non-homologous pairing and segregation. Hereditas, 48, 59-82.

ROBERTS, P. 1962. Interchromosomal effects and the relation between crossing-over and nondisjunction. Genetics, 47, 1691-1710.

SZAUTER, P. 1984. An analysis of regional constraints on exchange in Drosophila melanogaster using recombinationdefective meiotic mutants. Genetics, 100, 45-71.

TURNER, J. R. G. 1979. Genetic control of recombination in the silkworm. I. Multigenic control of chromosome 2. Heredity, $43,273-292$.

WHite, M. J. D. 1973. Animal Cytology and Evolution (3rd edn.). Cambridge University Press, London.

WEINSTEIN, A. 1936. The theory of multiple strand crossing over. Genetics, 21, 151-199.

WEINSTEIN, A. 1958. The geometry and mechanics of crossing over. Cold Spring Harb. Symp. Quant. Biol., 23, 177-195. 